\section{Study of inter-relationship of depression, seizure frequency and quality of life of people with epilepsy in India}

\author{
Shubham Mehta, Alok Tyagi, Richa \\ Tripathi, Mahesh Kumar \\ Department of Psychiatry, SMS Medical \\ College, Jaipur, Rajasthan, India
}

\section{Abstract}

Epilepsy is a chronic neurological disorder that can have profound physical, social and psychological consequences. We aimed to assess the clinical predictors of quality of life of people with epilepsy. We recruited 31 patients suffering from epilepsy in this crosssectional study. Their clinical profile was recorded. Quality of Life in Epilepsy (QOLIE31) was used to assess quality of life of our patients. Depression was screened by Neurological Disorders Depression Inventory in Epilepsy (NDDI-E). Among all the clinical variables, only seizure frequency significantly correlated with seizure worry $(\mathrm{P}=0.002)$, emotional well-being $(\mathrm{P}=0.026)$ and social functions ( $\mathrm{P}=0.013)$ subscales of QOLIE-31. NDDIE score showed a significant negative correlation with all the subscales of QOLIE-31 except medication effects $(\mathrm{P}=0.993)$. A significant positive correlation was also noted between seizure frequency and NDDI-E score $(r=0.417$, $\mathrm{P}=0.020$ ). Seizure frequency and depression are the most important predictors of quality of life in epilepsy patients. The management of patients with epilepsy should not only be aimed at just preventing seizures but the treating clinicians should also be cognizant about depression which itself can significantly affect the quality of life of patients.

\section{Introduction}

Epilepsy is a chronic neurological disorder that affects individuals of all ages regardless of gender. The impact of living with epilepsy can be enormous than the seizure itself. A World Health Organization (WHO) report estimated that $10 \%$ of the global burden of brain and mental disorders is caused by epilepsy, calculated in form of disability-adjusted life years (DALYs). ${ }^{1}$

Epilepsy can have diverse and complex effects on the overall well-being or subjective quality of life (QOL) of its sufferers.2,3 It can be associated with profound physical, psychological and social consequences and its impact on a person's quality of life can be greater than that of some other chronic conditions. 4,5

Several aspects directly related to epilepsy, including disease duration, age of onset, seizure severity and seizure frequency, are considered to affect the QOL of patients with epilepsy. However, one factor that has consistently been shown to be predictive of QOL in epilepsy is seizure frequency. ${ }^{6}$ Individuals with uncontrolled epilepsy often feel that they are a burden to others, especially because their condition limits many of their activities.

Also, people with seizures are more likely to have mental illness or psychological stress, to be physically inactive, or to report physical ailments. ${ }^{7}$

Depression and anxiety have been reported to be the most common psychological co-morbidities with epilepsy. ${ }^{7}$ Multiple studies have confirmed that mood is one of the strongest predictors of Q0L, even when other factors such as seizure severity or frequency are accounted for. ${ }^{8-10}$ A review of several studies also indicated that depression has been consistently associated with a poorer QOL in patients with epilepsy regardless of antiepileptic drug (AED) response. ${ }^{7}$

With this backdrop, we planned this study to assess the impact of seizure frequency and depression on QOL of epilepsy patients in our settings as there is relative paucity of Indian research in this regard.

The main aim of our study was to assess the quality of life of patients of epilepsy and determine its clinical predictors.

We hypothesized that depression and seizure frequency would affect all the domains and thus overall quality of life of epilepsy patients. Our second hypothesis was that seizure frequency and hence seizure control would predict the occurrence of depression in our patients.

\section{Materials and Methods}

This was a cross-sectional study in design. 31 patients with epilepsy who were attending the follow-up at our psychiatry outpatient department were recruited for this study. We included only the patients of epilepsy who had been diagnosed for at least one year. The subjects were not categorized according to type of epilepsy as the previous studies suggest that type of epilepsy is not an important predictor of Q0L.11,12 People with psychotic disorders, stroke, head injury, brain tumors, mental retardation, co-morbid chronic medical disorders like diabetes, hypertension and asthma and patients who have had recent brain surgery were excluded from the study. After taking the written informed consent for participation in the study, the patients were then subjected to
Correspondence: Shubham Mehta, Department of Psychiatry, SMS Medical College, Room 9, N.M.H.P. Trainees Hostel, Psychiatric Centre Campus, Sethi Colony, Jaipur 302004, Rajasthan, India. Tel. +91.979.972.3735.

E-mail: drshubhammehta@gmail.com

Key words: quality of life, depression, epilepsy

Contributions: the authors contributed equally.

Conflict of interests: the authors declare no potential conflict of interests.

Received for publication: 16 November 2013. Accepted for publication: 25 February 2014.

This work is licensed under a Creative Commons Attribution NonCommercial 3.0 License (CC BYNC 3.0).

(C) Copyright S. Mehta et al., 2014

Licensee PAGEPress, Italy

Mental Illness 2014; 6:5169

doi:10.4081/mi.2014.5169

evaluation by study instruments.

Socio-demographic performa: this included patient's age, sex, marital status, occupation, educational status, religion, family type, locality.

Clinical profile sheet: this consisted of clinical variables directly related to epilepsy like age of onset of seizures, duration of illness, seizure frequency, history of epilepsy in firstdegree relatives and type of anti-epileptic drug (AED) being given. We chose to look at seizure frequency at three levels $(0,1$, or $>1)$ rather than as a continuous variable to minimize inaccuracies related to participants' recall of number of seizures. 13

Neurological Disorders Depression Inventory in Epilepsy (NDDI-E):14 it is a six-item selfadministered tool designed to assess patients with epilepsy for depression. Each item is rated on 4-point likert scale with rating as 1never, 2-rarely, 3-sometimes, 4-always/often. Total score ranges from 6-24. A score of 14 and higher is suggestive of the possibility of a major depressive disorder and serves as a indicator to carry out a more in-depth evaluation.

Quality Of Life in Epilepsy (QOLIE-31):15 it consists of seven subscales which are seizure worry (5 items), emotional well-being ( 5 items), energy/fatigue (4 items), cognitive functioning ( 6 items), medication effects (3 items), social functioning (5 items), overall Q0L (2 items) and overall health (1 item). The responses used Likert rating scales which were later transformed into linear scales that ranged between 0 and 100 . Higher the score, better is the quality of life. The scoring and weightage of each item in the Q0LIE-31 was obtained from the guidelines in the QOLIE-31 manual. 
Data were analyzed using the Statistical Package of Social Sciences (SPSS) version 17.0. Descriptive statistics were expressed as mean [standard deviation (SD)] and frequency (percentage) as appropriate. Correlation coefficient was used to measure the relationship between NDDI-E total score, frequency of seizures and score of Q0LIE-31 subscales. The level of significance was set at $\mathrm{P}<0.05$.

\section{Results}

The age of patients ranged from 18-65 years with the mean (SD) of 33.74 (11.16) years. Table 1 shows socio-demographic profile of our study sample. Most of the patients were males (74.2\%), married (77.4\%), unskilled/semiskilled/skilled workers (70.96\%), educated up to middle school $(77.4 \%)$, of Hindu religion (77.4\%), having nuclear family (66.67\%) and coming from rural locality (70.96\%).

The age of patients showed a significant positive correlation with overall QOL domain $(\mathrm{r}=0.424, \mathrm{P}=0.017)$.

The mean (SD) age of onset of epilepsy in our patients was 19.66 years (10.96). Mean (SD) duration of illness i.e. epilepsy was 14.35 years (11.42). Mean (SD) duration of AED use was 12.18 years (10.18). Out of 31 , only 7 patients (22.58\%) had history of epilepsy in first-degree relatives; 8 patients reported zero seizures, same number of patients reporting one seizure and 15 patients reported $>1$ seizure in last six months.

Table 2 shows distribution of AEDs used by the study subjects. Almost half (48.4\%) of them were on two AEDs. Carbamazepine was the most commonly used AED followed by Sodium Valproate. Three patients were using an antidepressant.

The mean (SD) score of NDDI-E for our sample was 14.45 (4.28). Table 3 shows the mean scores of various QOLIE-31 subscales. The mean (SD) total score for Q0LIE-31 was 59.53 (17.59). The highest mean (SD) score was for the medication effects subscale, 88.08 (22.92) and lowest was for seizure worry, 51.82 (32.77).

Seizure frequency as denoted by number of seizures in past six months was found to be significantly correlated with seizure worry $(\mathrm{P}=0.002)$, emotional well-being $(\mathrm{P}=0.026)$ and social functions $(\mathrm{P}=0.013)$ subscales of QOLIE-31 as shown in Table 4.

NDDI-E score showed a significant negative correlation with all the subscales of QOLIE-31 except medication effects $(\mathrm{P}=0.993)$ as also shown in Table 4.

A significant positive correlation was also noted between seizure frequency and NDDI-E score $(\mathrm{r}=0.417, \mathrm{P}=0.020)$.

\section{Discussion}

The focus of this study was to assess the factors affecting the quality of life of patients with epilepsy.

\section{Clinical variables and quality of life in epilepsy}

Duration of illness did not affect any of the domains of quality of life in epilepsy. This is in accordance with the findings of a study by Norsa'adah et al., which also found no significant association between duration of epilepsy and QOL, although they noted lower scores of QOL in those who had longer duration of illness. ${ }^{11}$ As opposed to our findings, longer duration of epilepsy has been reported as a predictor for poor QOL in some earlier studies. ${ }^{12,16}$

Age of patients rather affected the overall QOL but age of onset of epilepsy did not. This is supported by similar results from previous studies. ${ }^{12,16-19}$

Duration and type of AEDs use had no significant affection on Q0LIE-31 score. Some authors have raised the doubts about the ability to evaluate the impact of AEDs on the quality of life, since this aspect has only a minor impact on calculation of the scores in QOLIE31.20

Seizure frequency was the only clinical variable which had significant impact on some domains of quality of life of epilepsy patients. In general, the literature supports the finding of our study in which people with frequent seizures had significantly poorer quality of life than those with infrequent or no seizures.3,11,17-22 Baker et al. reported that seizures frequency was the most important clinical predictor of psychosocial and emotional maladjustment in patients with epilepsy. 12 Seizure frequency was negatively correlated with subscale scores of seizure worry, emotional well-being and social functions. Probably, people with uncontrolled or poorly controlled epileptic seizures may feel uncomfortable most of the times because of not knowing when the next seizure will occur. Thus to avoid having seizures at inappropriate times, public places or social events, they may take precautions or impose restrictions on themselves by not visiting such places or events. They may be restricted or feel apprehensive themselves while driving, and may be denied employment and career opportunities which can translate into a lower QOL. Frequency of seizures has been related to fear and misunderstanding which results in the social stigma and discrimination surrounding epilepsy. A study by Chomba et al. reported that many patients with epilepsy were feared and rejected by families or communities. ${ }^{23}$ Cultural
Table 1. Socio-demographic profile of the patients.

\begin{tabular}{lc} 
Variable & $\begin{array}{c}\text { Frequency } \\
(\%)\end{array}$ \\
Sex & \\
Male & $23(74.2)$ \\
Female & $8(25.8)$ \\
Marital status & \\
Married & $24(77.4)$ \\
Unmarried & $7(22.58)$ \\
\hline Educational status & \\
Upto middle school & $24(77.4)$ \\
Middle to sr. secondary & $5(16.1)$ \\
Grad/post-grad & $2(6.45)$ \\
Occupation & \\
Unemployed & $7(22.58)$ \\
Unskilled/semi-skilled/skilled worker & $22(70.96)$ \\
Professional & $2(6.45)$ \\
\hline Religion & $24(77.4)$ \\
Hindu & \\
Muslim & $7(22.58)$ \\
Family type & \\
Nuclear & \\
Nuclear extended & $20(66.67)$ \\
Joint & $1(3.22)$ \\
\hline Locality & $10(32.26)$ \\
Rural & \\
Urban & $22(70.96)$ \\
\hline
\end{tabular}

Table 2. Anti-epileptic drugs used by patients.

\begin{tabular}{lc}
\hline Drug & Frequency (\%) \\
Carbamazepine & $17(54.83)$ \\
Sodium valproate & $16(51.61)$ \\
\hline Phenytoin & $5(16.1)$ \\
Clonazepam & $10(32.26)$ \\
\hline Lorazepam & $5(16.1)$ \\
Clobazam & $4(12.9)$ \\
\hline One type & $4(12.9)$ \\
Two types & $15(48.38)$ \\
\hline Three types & $12(38.70)$ \\
\hline
\end{tabular}

Table 3. Mean scores of QOLIE-31 subscales.

\begin{tabular}{lc}
\hline Subscale of Q0LIE-31 & Mean (SD) \\
\hline Seizure worry & $51.82(32.77)$ \\
Emotional well-being & $57.68(22.74)$ \\
\hline Energy/Fatigue & $52.10(13.40)$ \\
Cognitive & $61.95(23.94)$ \\
\hline Medication effects & $88.08(22.92)$ \\
Social functions & $64.98(28.36)$ \\
\hline Overall QOL & $54.27(12.67)$ \\
$\begin{array}{l}\text { Subjective overall health } \\
\text { (Item 31-visual analogue scale) }\end{array}$ & $59.35(14.13)$ \\
\hline Total score & $59.53(17.59)$ \\
\hline
\end{tabular}


Table 4. Correlation of seizure frequency with QOLIE-31 subscales and correlation of NDDI-E score with QOLIE-31 subscale score.

\begin{tabular}{lccccccccc} 
& $\begin{array}{c}\text { Seizure } \\
\text { worry }\end{array}$ & $\begin{array}{c}\text { Emotional } \\
\text { well-being }\end{array}$ & $\begin{array}{c}\text { Energy/ } \\
\text { fatigue }\end{array}$ & Cognitive & $\begin{array}{c}\text { Medication } \\
\text { effects }\end{array}$ & $\begin{array}{c}\text { Social } \\
\text { functions }\end{array}$ & $\begin{array}{c}\text { Q-31 } \\
\text { Overall } \\
\text { Q0L }\end{array}$ \\
Seizure frequency & (r, P) & -0.525 & -0.399 & -0.066 & -0.334 & 0.190 & -0.440 & -0.326 & -0.327 \\
& $0.002^{* *}$ & $0.026^{*}$ & 0.726 & 0.066 & 0.307 & $0.013^{*}$ & 0.074 & 0.073 \\
NDDI-E (r, P) & -0.704 & 0.883 & -0.646 & 0.602 & -0.002 & -0.723 & -0.705 & -0.867 \\
& $0.0001^{* *}$ & $0.0001^{* *}$ & $0.0001^{* *}$ & $0.0001^{* *}$ & 0.993 & $0.0001^{* *}$ & $0.0001^{* *}$ & $0.0001^{* *}$ \\
\hline
\end{tabular}

${ }^{\circ}$ Number of Seizures in Last six Months. r, pearson's correlation; ${ }^{*} \mathrm{P}<0.05 ; * * \mathrm{P}<0.01$.

beliefs influence attitudes and actions of the community towards patients with epilepsy and high rates of psychological problems like anxiety, depression, and low self-esteem have been reported in patients with epilepsy, thus adversely affecting emotional well-being and social functioning of patients. ${ }^{24-26}$

However, there was no significant correlation of frequency of seizures with energy, cognitive and overall QOL domains of QOLIE-31 which is in contradiction to findings from some previous studies. ${ }^{10,11,15,27}$

\section{Depression and quality of life in epilepsy}

It is known that in epileptic patients, psychiatric disturbances are prevalent and depression is the most frequent co-morbidity. 9,28

Depression showed a strong negative affection of the QOL, and also a significant correlation between the total QOLIE-31 score and subscale scores in the domains of seizure worry, emotional well-being, energy/fatigue, cognitive, social functions and subjective overall health (Item-31).9,28,29 Strongest correlation between depression and emotional well being dimension seems to be self-explanatory. The more a person with epilepsy feels depressed the more nervous, restless and down-hearted he is. Furthermore, depression appeared to be the stronger predictor of QOL in epilepsy than seizure frequency. In some studies, the presence of depression has been indicated as an essential factor influencing the patient's judgment concerning his Q0L. This can partly be explained by the fact that QOL inventories reflect social and psychological domains more than the clinical aspects, and thus being the subjective measures that the individual uses to report on his/her perception of their QOL. Also, there are evidences that psychological factors contribute 30 to $35 \%$ or up to $50 \%$ to the variation in Q0L, as compared to values of about $20 \%$ for the clinical variables related to epilepsy. $9,30,31$

Thus our first hypothesis was rejected as depression affects all the domains of QOLIE-31 but seizure frequency is found to affect only three domains.

NDDI-E score was also directly correlated with the frequency of seizures in past six months implying that lack of seizure control might lead to depression in epilepsy patients. This approves our second hypothesis that occurrence of depression in epilepsy bears an association with seizure frequency. A recent study by Dias et al., also concluded that major depression is associated with uncontrolled seizures, with a prevalence twice that of patients whose seizures are controlled. ${ }^{13}$

\section{Limitations}

Our study had some limitations like smallsample size and a cross-sectional design, thus our findings cannot be generalized. Also, we did not control for use of AEDs while carrying out the study which might have confounded our results to an extent.

\section{Conclusions}

Seizure frequency and depression are the most important predictors of quality of life in epilepsy patients. The management of patients with epilepsy should not only be aimed at just preventing seizures but the treating clinicians should also be cognizant about depression which itself can significantly affect the quality of life of patients. Reintegration of the sufferers into community should also be one of the primary goals of management in epilepsy.

\section{References}

1. WHO. Global campaign against epilepsy: out of the shadows. Available from: www.who.int/mental_health/management/en/ GcaeBroEn.pdf.

2. Sillanpaa M, Haataja L, Shinnar S. Perceived impact of childhood onset epilepsy on quality of life as an adult. Epilepsia 2004;45:971-7.

3. Mrabet H, Mrabet A, Zouari B, Ghachem R. Health-related quality of life of people with epilepsy compared with a general reference population: a Tunisian study. Epilepsia 2004;45:838-43.

4. International League Against Epilepsy. Epilepsy: out of the shadows: European declaration on epilepsy. Epilepsia 2003;44:
2-3.

5. International League Against Epilepsy. Quality of life: general considerations. Epilepsia 2003;44:57-8.

6. Wheless JW. Intractable epilepsy: a survey of patients and caregivers. Epilepsy Behav 2006;8:756-64.

7. Jacoby A, Snape D, Baker GA. Determinants of quality of life in people with epilepsy. Neurol Clin 2009;27:843-63.

8. Gilliam F, Hecimovic H, Sheline Y. Psychiatric comorbidity, health, and function in epilepsy. Epilepsy Behav 2003;4: S26-30.

9. Johnson EK, Jones JE, Seidenberg M, Hermann BP. The relative impact of anxiety, depression and clinical seizure features on health related quality of life in epilepsy. Epilepsia 2004;45:544-50.

10. Tracy JI, Dechant V, Sperling MR, et al. The association of mood with quality of life ratings in epilepsy. Neurology 2007;68:11017.

11. Norsa'adah B, Zainab J, Knight A. The quality of life of people with epilepsy at a tertiary referral centre in Malaysia. Health Qual Life Outcomes 2013;11:143.

12. Baker AG, Jacoby A, Buck D, et al. Quality of life of people with epilepsy: a European study. Epilepsia 1997;38:353-62.

13. Dias R, Bateman LM, Farias ST, et al. Depression in epilepsy is associated with lack of seizure control. Epilepsy Behav 2010;19:445-7.

14. Gilliam FG, Barry JJ, Hermann BP, et al. Rapid detection of major depression in epilepsy: a multicentre study. Lancet Neurol 2006;5:399-405.

15. Vickrey BG, Perrine KR, Hays RD, et al. Quality of life in epilepsy QOLIE-31 (Version 1.0): scoring manual and patient inventory. Santa Monica: Rand; 1993.

16. Djibuti M, Shakarishvili R. Influence of clinical, demographic and socioeconomic variables on quality of life in patients with epilepsy: findings from Georgian study. $\mathrm{J}$ Neurol Neurosurg Psychiatry 2003;74:5703.

17. Berto P. Quality of the life in patients with epilepsy and impact of treatment. Pharmacoeconomics 2002;20:1039-59.

18. Johnson EK, Jones JE, Seidemberg M, Hermann BP. The relative impact of anxi- 
ety, depression, and clinical seizure features on health related quality of life in epilepsy. Epilepsia 2004;45:544-50.

19. Taylor RS, Sander JW, Taylor RJ, Baker GA. Predictors of health-related quality of life and costs in adults with epilepsy: a systematic review. Epilepsia 2011;52:2168-80

20. Auriel E, Landov H, Blatt I et al. Quality of life in seizure-free patients with epilepsy on monotherapy. Epilepsy Behav 2009;14:130-3.

21. Alanis-Guevara I, Pena E, Corona T, et al. Sleep disturbances, socioeconomic status, and seizure control as main predictors of quality of life in epilepsy. Epilepsy Behav 2005;7:481-5.

22. Baker GA, Gagnon D, McNulty P. The relationship between seizure frequency, seizure type and quality of life: findings from three European countries. Epilepsy
Res 1998;30:231-40.

23. Chomba EN, Haworth A, Atadzhanov M, et al. Zambian health care workers' knowledge, attitudes, beliefs, and practices regarding epilepsy. Epilepsy Behav 2007;10:111-9.

24. Ramasundrum V, Mohd Hussin ZA, Tan CT. Public awareness, attitudes and understanding towards epilepsy in Kelantan, Malaysia. Neurol J Southeast Asia 2000;5: 55-60.

25. Sharkawy GE, Newton C, Hartley S. Attitudes and practices of families and health care personnel toward children with epilepsy in Kilifi, Kenya. Epilepsy Behav 2006;8:201-12.

26. Baker GA. The psychosocial burden of epilepsy. Epilepsia 2002;43:26-30.

27. Harden CL, Maroof DA, Nikolov B, et al. The effect of seizure severity on quality of life in epilepsy. Epilepsy Behav 2007; 11:208-11.

28. Kanner AM, Barry JJ, Gilliam F, et al. Anxiety disorders, subsyndromic depressive episodes, and major depressive episodes: do they differ on their impact on the quality of life of patients with epilepsy? Epilepsia 2010;51:1152-8.

29. Kwan P, Yu E, Leung $H$, et al. Association of subjective anxiety, depression, and sleep disturbance with quality-of-life ratings in adults with epilepsy. Epilepsia 2009;50: 1059-66.

30. Boylan LS, Flint LA, Labovitz DL, et al. Depression but not seizure frequency predicts quality of life in treatment-resistant epilepsy. Neurology 2004;62:258-61.

31. Cramer JA, Arrigo C, van Hammee G, et al. Effect of levetiracetam on epilepsy related quality of life. Epilepsia 2000;41:868-74. 